\title{
Effects of carboxymethyl cellulose extracted from oil palm empty fruit bunch stalk fibres on the physical properties of low-fat ice cream
}

\author{
Parid, D.M., "Rahman, N.A.A., Baharuddin, A.S., Kadir Basha, R., P. Mohammed, M.A., \\ Mat Johari, A. and Abd Razak, S.Z. \\ Department of Process and Food Engineering, Faculty of Engineering, Universiti Putra Malaysia, 43400 \\ UPM Serdang, Selangor, Malaysia.
}

\begin{abstract}
Article history:
Received: 12 April 2020

Received in revised form: 18 May 2020

Accepted: 21 June 2020

Available Online: 3 January 2021
\end{abstract}

\section{Keywords:}

Carboxymethyl cellulose (CMC),

Oil palm empty fruit bunch (OPEFB),

Ice cream,

Dairy processing

DOI:

https://doi.org/10.26656/fr.2017.5(S1).017

\begin{abstract}
Carboxymethyl cellulose (CMC) is a food additive that plays an important role in the structure-forming of most food. The current extraction of CMC from wood has created competition with the wood industries. To ensure the sustainability of CMC, the search for alternatives to wood is critical. A study on the extraction of CMC from oil palm empty fruit bunch (OPEFB) stalk fibres (SCMC) was successfully carried out previously by the authors. In this study, the potential application of SCMC on low-fat ice cream properties was investigated. Liquid ice cream mix with SCMC had a higher viscosity (129.4 cP) when compared to the control sample $(25.5 \mathrm{cP})$. However, the viscosity of liquid ice cream mix produced using SCMC was slightly lower than the one produced using the commercial CMC (360 cP). The overrun of the SCMC low-fat ice cream was slightly lower $(35.2 \%)$ than the one produced using commercial CMC (41.5\%). The resistance of SCMC and commercial CMC low-fat ice creams towards melting were about the same (60.28\% and 58.75\% respectively). The commercial CMC produced slightly harder (38.19 $\mathrm{N})$ ice cream than the one with SCMC $(28.88 \mathrm{~N})$. Thus, the low-fat ice cream produced using SCMC is comparable with the low-fat ice cream produced using commercial CMC. This indicates the reliability of the extracted CMC from OPEFB stalk fibres to be applied in food, and thus creates a complete solution for the utilization of palm oil mill by-product to produce a value-added product.
\end{abstract}

\section{Introduction}

Ice cream is a popular frozen dessert among all ages. Freezing and whipping processes during manufacturing is crucial in order to obtain high-quality ice cream in terms of texture, structure and palatability. There are various formulations or recipes produced by manufacturers that influence the acceptability and preference of consumers. Ice cream comprises approximately $30 \%$ water, $50 \%$ air, $5 \%$ fat and $15 \%$ matrix (sugar solution) by volume (Clarke, 2004). An ice cream comprised of four main distinct phases: solid ice crystals, fat globules, air bubbles and liquid unfrozen serum phase (Rahman et al., 2013). It is essential to know the reason why certain ingredients are being added, why the process is time consuming and why certain processes are needed in making ice cream. Ice cream can be categorized based on its fat content i.e. low -fat (3-5\% fat), light (6-8\%) and hard- or soft-frozen ice cream (more than $10 \%$ fat).
Texture and flavour attributes are important in producing high-quality ice cream. Flavour is a chemosensory characteristic sensed by the receptors found in the tongue and nose, while the texture is entirely discerned in the mouth during mastication process (Taylor and Linforth, 1996, Kilcast and Clegg, 2002). There are three classifications of ice cream that are commercially available which are premium, standard and economy. Premium ice cream is typically prepared from selected quality ingredients and has a relatively high amount of dairy fat and low amount of air. In contrast, economy ice cream is made from cheaper ingredients such as vegetable fats and comprises more air. Ice cream manufacturers have to face the challenges in choosing the best composition especially when the considerations include legal requirements, quality of the product, raw materials available, plant equipment and processes, trade demands, competition and cost.

The attempts to transform OPEFB into value-added products have gained wide attention since OPEFB is one 
of the most produced biomasses from oil palm refineries and is known to contain rich source of cellulose. Cellulose must be transformed into its derivatives to be used in the food industry, such as carboxymethyl cellulose (CMC). Extraction of CMC from oil palm fibres is favorable in Malaysia due to the abundance of oil palm biomass in the plantation. OPEFB, which is made up of lignocellulosic components is used as the raw material to produce $\mathrm{CMC}$.

$\mathrm{CMC}$ acts as a stabilizer and functional ingredient in ice cream. The solubility of this cellulose derivative in cold and hot water causes the modification of rheological properties and consequently produces the right structure and texture of ice cream. Only a small amount of CMC is needed to be utilized to achieve its credit functionality to ice cream texture and condition. $0.5 \% \mathrm{w} / \mathrm{w}$ is the highest amount of stabilizer in ice cream. The texture, which can be defined as the physical and mouthfeel characteristics of a food or drink, is very unique in ice cream due to the fact that it contains all three states of matter: solid (found in the ice crystals and fat globules), liquid (found in the sugar solution), and gas (found in the air bubbles).

This study focuses on the potential application of the extracted CMC from OPEFB stalk fibres on low-fat ice cream. The physical properties i.e. viscosity of liquid ice cream mix; and also, the overrun, melting characteristics and hardness of ice cream were investigated.

\section{Materials and Method}

\subsection{Materials}

The OPEFB were obtained from Felda Sungai Tengi palm oil mill (Selangor, Malaysia) after the fruitlets have been removed (Figure 1). The OPEFB was stored in a $20^{\circ} \mathrm{C}$ deep freezer to prevent fungal contamination. The spikelets of the OPEFB were omitted manually in order to obtain the OPEFB stalks. The shredded stalk fibres from the stalk bundle were cleansed with $2 \%$ detergent solution and rinsed with tap water to withdraw any of the dust and oil leftover. Then, the clean OPEFB stalks fibres were dried in an oven at $60^{\circ} \mathrm{C}$ for $24 \mathrm{hrs}$. Afterwards, the dried OPEFB stalk fibres were grounded into $0.2 \mathrm{~mm}$ powder by using a power-cutting mill (Retsch Technology GmbH, SM 200, Haan, Germany) as explained by Parid et al. (2018).

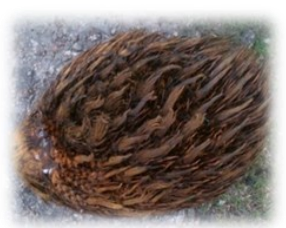

(a)

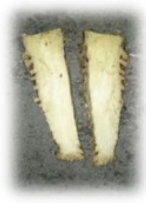

(b)

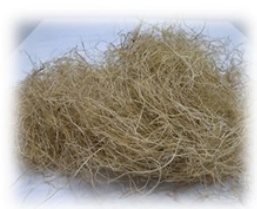

(c)
Figure 1. (a) Whole bunch of OPEFB, (b) OPEFB stalk bundle and (c) shredded OPEFB stalk fibres (Parid et al., 2018)

\subsection{Preparation of carboxymethyl cellulose from OPEFB} (SCMC)

The carboxymethyl cellulose obtained from OPEFB stalk fibres (SCMC) was extracted based on the method explained by Parid et al. (2018).

\subsection{1 $\alpha$-cellulose extraction from OPEFB stalk fibres}

A total of 10 bunches of powdered OPEFB stalk fibres were treated with $0.7 \%(\mathrm{w} / \mathrm{v})$ sodium chlorite $\left(\mathrm{NaClO}_{2}\right)$ solution at $70^{\circ} \mathrm{C}$ to $80^{\circ} \mathrm{C}$ for $2 \mathrm{hrs}$ repeatedly for five times. The sodium chlorite $\left(\mathrm{NaClO}_{2}\right)$ solution was acidified with acetic acid until the $\mathrm{pH}$ reached 4 prior to the bleaching process by treating the OPEFB stalk fibres with a fibre: $\mathrm{NaClO}_{2}$ solution ratio of $1: 50 \mathrm{~g} /$ $\left.\mathrm{mL}^{-1}\right)$. The residues were washed and rinsed using distilled water to cleanse the yellowish colour and odour from the chlorine oxide throughout the bleaching process. The samples were dried at $60^{\circ} \mathrm{C}$ overnight. Then, the bleached fibres were treated with $17.5 \%(\mathrm{v} / \mathrm{v})$ sodium hydroxide $(\mathrm{NaOH})$ solution with a fibre: $\mathrm{NaOH}$ solution ratio of $1: 25\left(\mathrm{~g} / \mathrm{mL}^{-1}\right)$ for $2 \mathrm{hrs}$ at room temperature. Lastly, the mixture was filtered, washed, and oven-dried at $60^{\circ} \mathrm{C}$ for $24 \mathrm{hrs}$, which produced the $\alpha$ cellulose fibres as illustrated in Figure 2 (Xiang et al., 2016).

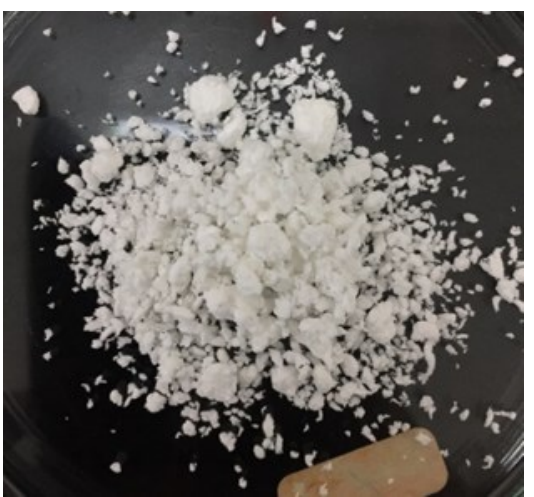

Figure 2. $\alpha$-cellulose extracted from OPEFB stalk fibres

\subsubsection{Production of carboxymethyl cellulose (SCMC) from OPEFB stalk fibres}

Carboxymethyl cellulose (CMC) extraction was carried out using monochloroacetate (MCA; BIS Chemicals, Shah Alam, Malaysia) in aqueous alkaline medium. Approximately $5.0 \mathrm{~g} \alpha$-cellulose from OPEFB stalk fibres was activated by dispersing it in $10 \mathrm{~mL}$ aqueous $\mathrm{NaOH}(30 \% \mathrm{v} / \mathrm{v})$ and the dispersion was diluted using $100 \mathrm{~mL}$ isopropyl alcohol as the solvent and stirred for an additional 15 mins at room temperature for $1 \mathrm{hr}$ for an alkalization process to take place. The process was to aid the cellulose to react during the carboxymethylation process. Carboxymethylation was done by adding $6.0 \mathrm{~g}$ of monochloroacetate (MCA; BIS Chemicals, Shah Alam, Malaysia) per $5.0 \mathrm{~g}$ cellulose to the dispersion. The process was carried out for $3 \mathrm{hrs}$ at 
$45^{\circ} \mathrm{C}$. The mixture was then adjusted to attain neutral $\mathrm{pH}$ with glacial acetic acid. The product obtained (SCMC) was soaked in $300 \mathrm{~mL}$ of absolute methanol overnight to remove impurities. The purification step commenced by washing the solid that was obtained using $70 \%$ ethanol followed by $99.7 \%$ ethanol, three times, to eliminate the undesirable by-products. The CMC was obtained at a constant weight at $60^{\circ} \mathrm{C}$ (Pushpamalar et al., 2006). Figure 3 shows the final SCMC extracted from OPEFB stalk fibres. The characteristics of the commercial CMC was also reported previously by Parid et al. (2018).

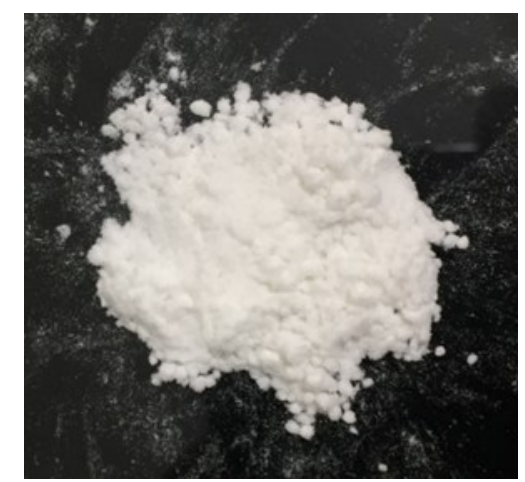

Figure 2. $\alpha$-cellulose extracted from OPEFB stalk fibres

\subsection{Application of carboxymethyl cellulose in low-fat ice cream}

The low-fat ice cream formulations were prepared based on the range stated by Goff and Hartel (2013) as shown in Table 1. Full cream milk, sugar, whey powder, creamer and flavouring were obtained from local suppliers. The emulsifier used was Olein PK-10 (BIS Chemicals, Shah Alam, Malaysia) and the commercial $\mathrm{CMC}$ used for comparison was purchased from Warisnove Sdn. Bhd.

The dry ingredients were dispersed under agitation into the wet ingredients at room temperature by manual stirring. The mixture was then batch pasteurized at $80^{\circ} \mathrm{C}$ for $15 \mathrm{~s}$ and consequently made to go through the twostage homogenization process using a laboratory-scale homogenizer. Then, the liquid ice cream mixture was rapidly cooled at a constant temperature of $4^{\circ} \mathrm{C}$ overnight for ageing. The aged mixture was then frozen using a home-style batch ice cream machine (Breville, Model
BC1600, Australia) which has the maximum capacity of 1 litre. The ice cream was further hardened and stored in a deep freezer under quiescent freezing conditions at $20^{\circ} \mathrm{C}$. The fat, milk solids-non-fat (MSNF) and total solid contents of the final ice cream are $3.0 \%, 7.4 \%$, and $30.3 \%$, respectively.

\subsection{Apparent viscosity measurement of liquid ice cream mixture}

A digital viscometer (Brookfield, MA) was used to measure the apparent viscosity of $250 \mathrm{~mL}$ liquid ice cream mix under controlled room temperature after the ageing process. Spindle number 2 was used to take the measurements at a constant $\mathrm{rpm}$. Three measurements were taken per sample and the average values were used to plot the results.

\subsection{Overrun measurement}

Ice cream overrun was determined according to the method described by Marshall et al. (2003) by using the formula shown in equation:

$$
\text { Overrun (\%) }=\frac{M_{1}-M_{2}}{M_{2}} \times 100
$$

where, $M_{1}$ is the mass of the ice cream mixture $(\mathrm{g})$, and $M_{2}$ is the mass of the ice cream (g).

\subsection{Melting characteristics measurement}

The melting characteristics were determined from the melting rate and melting resistance of the samples. A day prior to melting analysis was carried out, the samples were transferred to a $-15^{\circ} \mathrm{C}$ freezer and left overnight. Hard ice cream block (200 g) was removed from the containers, put on a $1 \mathrm{~mm}$ wire screen mesh and allowed to melt under controlled room temperature (Figure 4). The time required for the dripping of the first drop of melted ice cream was recorded. The weight of the material passed through the screen was recorded at 5 mins time intervals for 60 mins duration. The melting rate was determined as the slope of the graphs of the dripped portion as a function of time and expressed in g. $\mathrm{g}^{-1}$ min. Melting resistance was evaluated by weighing

Table 1. Formulations of each low-fat ice cream sample

\begin{tabular}{cccc}
\hline \multirow{2}{*}{ Ingredients } & \multicolumn{1}{c}{ Ice cream with SCMC } & Ice cream with commercial CMC & Control sample \\
\cline { 2 - 4 } & $(\% \mathrm{w} / \mathrm{w})$ & $(\% \mathrm{w} / \mathrm{w})$ & $(\% \mathrm{w} / \mathrm{w})$ \\
\hline Water & 28.9 & 28.9 & 29 \\
Full cream milk & 46.5 & 46.5 & 46.5 \\
Sugar & 16.3 & 16.3 & 16.3 \\
Whey powder & 3.6 & 3.6 & 3.7 \\
Creamer & 3.6 & 3.6 & 3.7 \\
Emulsifier & 0.4 & 0.4 & 0.4 \\
Stabilizer & $0.3(\mathrm{SCMC})$ & $0.3($ comm CMC) & 0 \\
Flavouring & 0.4 & 0.4 & 0.4 \\
\hline
\end{tabular}


the melted ice cream after 25 and 45 mins at $25^{\circ} \mathrm{C}$ and expressed as the percent of the weight of the initial hard ice cream block. A uniform distribution of small ice crystals and air cells results in gradual melting, a phenomenon that can be attributed to a reduced rate of heat transfer, since the trapped air functions as thermal resistance layers (Muse and Hartel, 2004). Emulsifier also plays a critical role in meltdown rate due to its effect on fat structuring.

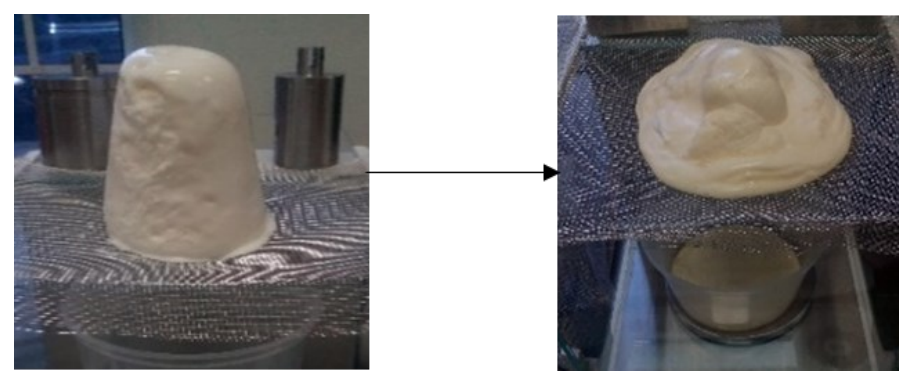

Figure 4. Hard ice cream samples for melting characteristics test.

\section{7 Hardness}

Before hardness analysis was conducted, the sample was transferred from $-20^{\circ} \mathrm{C}$ freezer to another freezer at $15^{\circ} \mathrm{C}$ and held for $24 \mathrm{hrs}$. Texture analyzer (TA.XT Plus, Stable Micro System, England) was used for determining the hardness of the samples. The thickness of the hard ice cream block was $5 \mathrm{~cm}$ and the experiment was conducted at $25^{\circ} \mathrm{C}$. For each sample, three measurements were carried out using a $45^{\circ}$ perspex cone probe. The penetration depth at the geometrical centre of the samples was $10 \mathrm{~mm}$ and the penetration speed was set at $2.0 \mathrm{~mm} \cdot \mathrm{s}^{-1}$. Hardness $(\mathrm{N})$ of the samples was determined as the peak compression force during penetration. The cone was warmed back to room temperature before subsequent measurement took place to prevent data variation.

\section{Results and discussion}

\subsection{Potential application of SCMC in low-fat ice cream}

Although the permissible amount of stabilizer used in ice cream is less than $0.5 \%$, it plays a very crucial role in maintaining the taste and textural quality of ice cream. $\mathrm{CMC}$ can be rapidly dissolved in hot or cold water as compared to other material (such as carrageenan and sodium alginate). $\mathrm{CMC}$ can create a great networking structure at various temperature since it is high in transparency and fluidity. Thus, CMC can be claimed as one of the most suitable stabilizers to be used in ice cream apart from locust bean gum and guar gum.

\subsection{Apparent viscosity of liquid ice cream mixture}

Figure 5 shows the effect of stabilizer on the viscosity of the liquid ice cream mixture. It is significant
$(\mathrm{P}<0.05)$ that liquid ice cream mixture made using commercial CMC has a higher viscosity $(360.0 \mathrm{cP})$ as compared to that of the extracted SCMC (129.4 cP). It can be said that this is due to the CMC properties themselves since the commercial $\mathrm{CMC}$ has higher viscosity as compared to that of the extracted CMC in water (Parid et al., 2018).

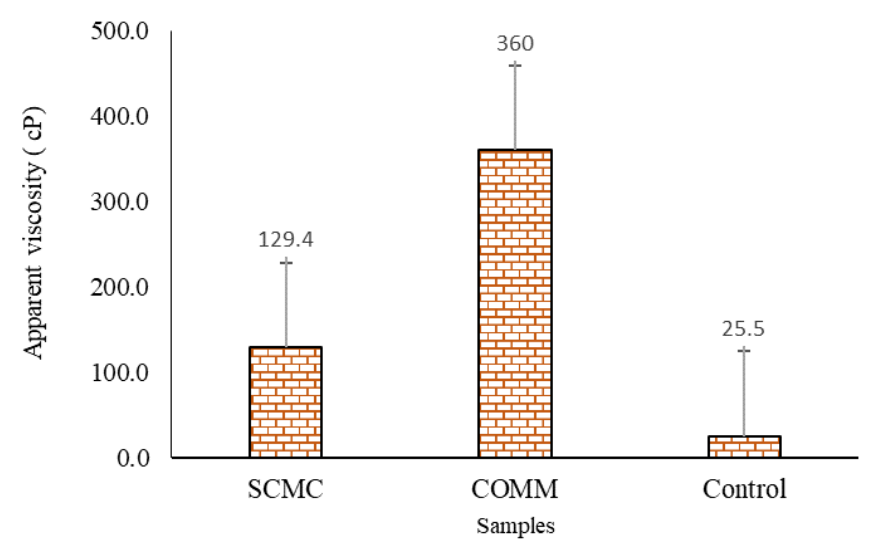

Figure 5. Effects of stabilizer on the apparent viscosity of liquid ice cream mixture.

The mixture produced with colloids gives double effects on its viscosity attribute. Prior to the homogenizing and ageing steps, the addition of CMC enhances the consistency of the liquid mixture. The texture of the liquid ice cream mixture will be more uniform since $\mathrm{CMC}$ has strong dispersion capability. CMC functions as a thickener mainly to provide viscosity in ice cream mixture, thus preventing the ice cream from layering due to the presence of fat and protein.

\subsection{Overrun of low-fat ice cream}

Overrun influences foam stability, texture, meltdown and sensory perception of ice cream. The incorporation of too much air produces fluffy ice cream and too little produces a soggy and heavy product. Sakurai et al. (1996) found that ice creams with low overruns melted quickly, whereas ice creams with high overruns began to melt slowly and had a good melting resistance. Figure 6 shows the overrun of the samples.

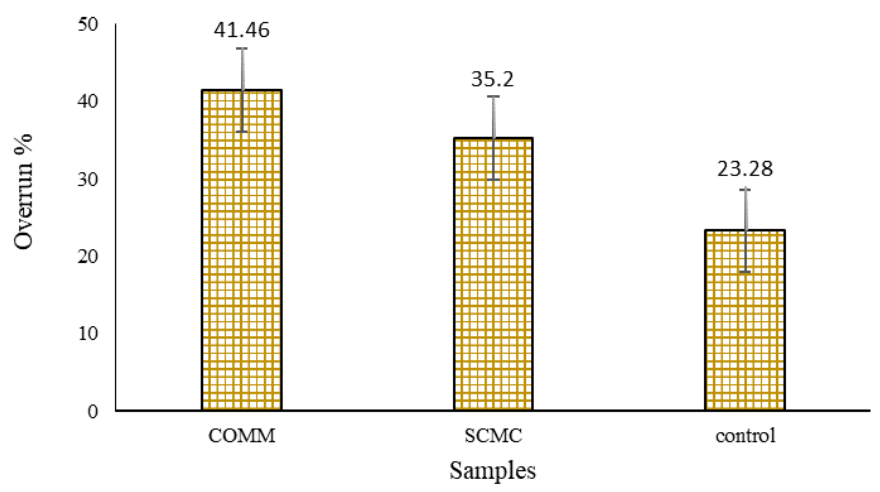

Figure 6. Effect of stabilizers on overrun of low-fat ice cream 
The overrun of the SCMC low-fat ice cream was slightly lower $(35.2 \%)$ than that of the one produced using commercial CMC (41.5\%). Higher overrun in ice cream made with $\mathrm{CMC}$ reflects the higher viscosity of its liquid mix as compared to other samples. The addition of $\mathrm{CMC}$ reduces the air cell size as compared to a similar ice cream mix made without CMC. During freezing, the air cell size might be possibly changed because it is directly attributed to the rheological properties of the ice cream. As freezing commenced, the apparent viscosity increased, which will decrease the maximum air cell size due to the increase in shear stress applied to disrupt the air cells. Results showed a direct correlation between the results of overrun and melting characteristics as the increase in overrun enhances the melting resistance.

The slower melting rate in the ice creams with high overruns was attributed to a reduced rate of heat transfer due to a larger volume of air but may also be due to the more tortuous path through which the melting fluid must flow. Stabilizers play an important role in increasing the volume of ice cream as it enhances the viscosity and retains the air bubbles (Hartel, 1996). The main factor that influences the melting rate, shape retention during the meltdown and the rheological properties of the ice cream mix is the structure of air cells that will largely contribute to the creaminess attribute. Smaller air cells enhance product quality (Moeenfard and Tehrani, 2008).

\subsection{Melting characteristics of low-fat ice cream}

Freeze-churning is the last key step in the production of ice cream. The ice cream is transformed from a liquid ice cream mix into a semi-solid material with delicate mouthfeel and swelling volume. The melt-down rate of ice cream is affected by many factors, including the amount of air incorporated, the nature of the ice crystals and the network of fat globules formed during freezing. As subjected to the hardness attribute, Rosalina et al. (2004) reported that ice creams with lower overruns were harder than those made with high overrun but melted more rapidly. The melt-down rate involves the relationship between the mass of the melted ice cream with time. Figure 7 shows the melting rate of low-fat ice creams produced from SCMC and commercial CMC together with the control sample. The results showed that the low-fat ice cream prepared using commercial CMC had a faster melting rate than the one prepared using SCMC.

Stabilizers increase the melting resistance of ice cream, due to their water holding and micro-viscosity enhancement ability (Bahrampavar and Mazaheri Tehrani, 2011; Muse and Hartel, 2004). Ice cream will lose its shape if it tends to melt quickly. As seen from Figure 7, low-fat ice cream prepared with no $\mathrm{CMC}$ (control) melted more rapidly. A fast-melting product is undesirable because it tends to become heat-shocked readily. It can also be seen that the low-fat ice cream prepared with commercial CMC and SCMC depicted good melting rate behaviours. The melting characteristics of ice cream were significantly affected by the presence of hydrocolloids due to its water-holding ability.

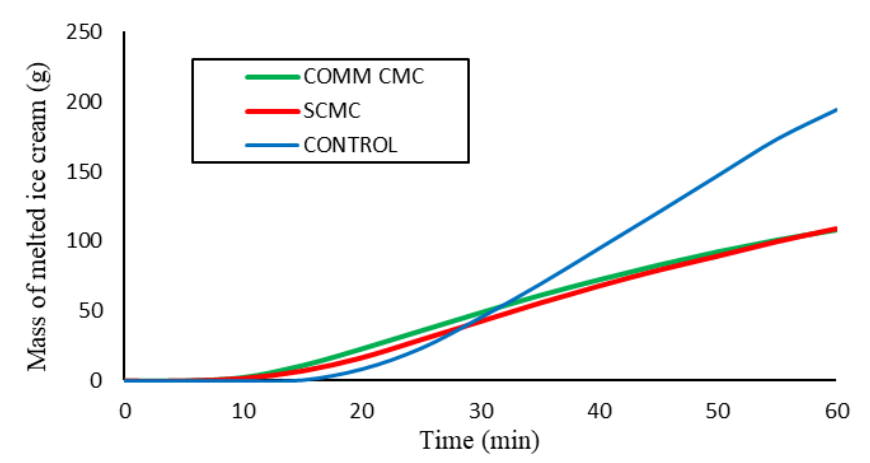

Figure 7. Effect of stabilizers on melt-down rate of low-fat ice cream.

On the other hand, the presence of CMC had a significant effect on melting resistance (Figure 8). The melting resistance of low-fat ice cream made with SCMC and commercial CMC was $60.28 \%$ and $58.75 \%$, respectively. Both samples had higher melting resistance as compared to the control sample (39.68\%) due to their higher melting rate behaviour.

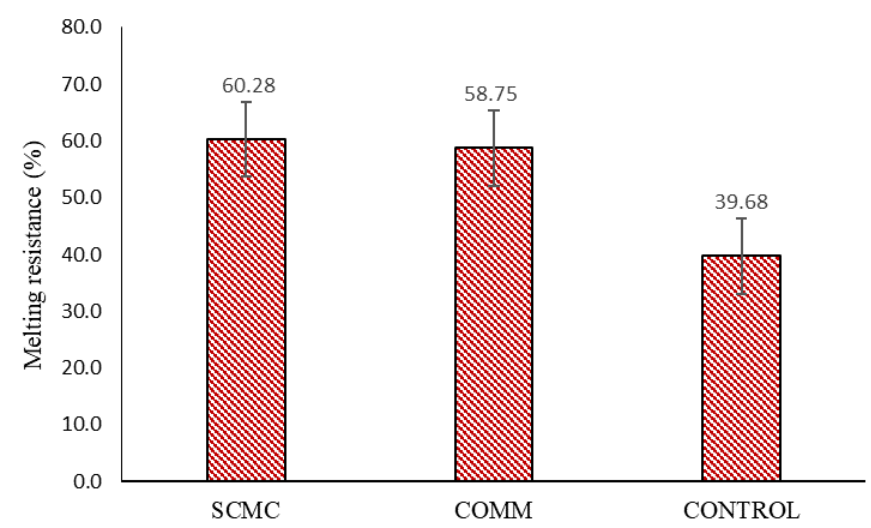

Figure 8. Effect of stabilizers on melting resistance of low-fat ice cream

When ice cream is exposed to the warm surrounding, heat transfer occurs. The heat starts to penetrate from the exterior surface of the ice cream and the ice starts to melt, while the local serum is still in its cold state. The melted ice then diffuses with the serum and due to the effect of gravity, the liquid eventually drips.

\subsection{Hardness of low-fat ice cream}

Figure 9 shows the hardness of the low-fat ice cream samples. The hardness of hard ice cream prepared using commercial CMC and SCMC depicted a statistically insignificant value $(P=0.190)$ than that of the hard ice 
cream prepared with commercial CMC $(38.19 \pm 59.06 \mathrm{~N})$ were harder as compared to hard ice cream produced with SCMC (28.88 $\pm 54.15 \mathrm{~N})$ (Fisher's test, $P<0.05)$.

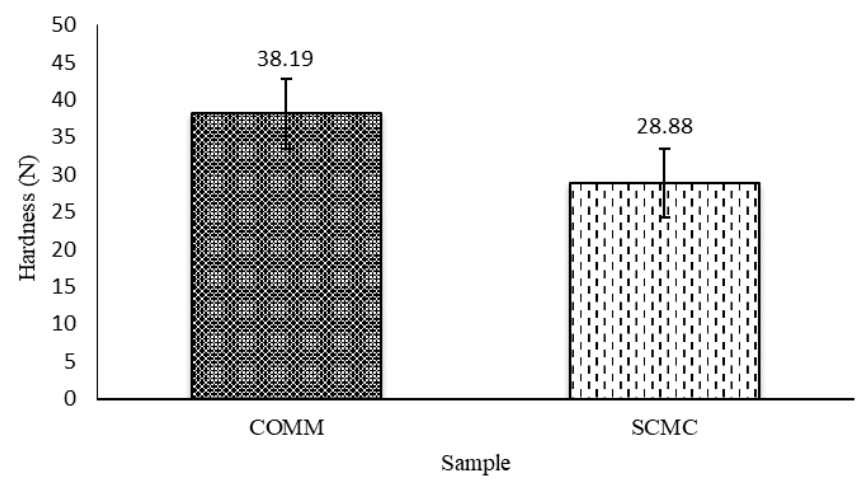

Figure 9. Effect of stabilizers on the hardness of hard ice cream.

The structure of ice cream depends on the size and shape of the ice crystals embedded in it. The hardness of ice cream is measured as the resistance of the ice cream to deformation when an external force is applied. Sakurai et al. (1996) found that ice creams with more large ice crystals were harder than ice creams that had fewer large ice crystals.

\section{Conclusion}

From the results obtained in this study, it can be seen that low-fat ice cream produced using SCMC is comparable with low-fat ice cream produced using commercial CMC. It is significant $(\mathrm{P}<0.05)$ that liquid ice cream mixture made using commercial CMC has a higher viscosity $(360.0 \mathrm{cP})$ when compared to that of the extracted SCMC (129.4 cP). Liquid ice cream mixture with SCMC had a higher viscosity $(129.4 \mathrm{cP})$ when compared to that of the control sample $(25.5 \mathrm{cP})$. SCMC ice cream has slightly lower overrun (35.2\%) than that of the ice cream produced using commercial CMC (41.5\%). The resistance of SCMC and commercial ice creams towards melting were about the same $(60.28 \%$ and $58.75 \%$, respectively). The commercial CMC produced slightly harder $(38.19 \mathrm{~N})$ ice cream than the one with SCMC $(28.88 \mathrm{~N})$. Thus, it can be concluded that the SCMC extracted from OPEFB stalk fibres is reliable to be applied in food. For further understanding and improvement, trials need to be done at an industrial scale using an industrial continuous ice cream freezer to truly evaluate the performance of SCMC in ice cream.

\section{Acknowledgements}

The authors were grateful for the support from the laboratory staff who helped in handling the equipment for the analyses involved in the research. This study was conducted in the laboratory of the Department of Process and Food Engineering, Faculty of Engineering, Universiti Putra Malaysia.

\section{References}

Bahrampavar, M. and Mazehari Tehrani, M. (2011). Application and functions of stabilizers in ice cream. Food Reviews International, 27(4), 389-407. https:// doi.org/10.1080/87559129.2011.563399

Clarke, C. (Ed.) (2004). Making ice cream in the factory. In Clarke, C. The Science of Ice Cream, p. 72-75, UK: The Royal Society of Chemistry.

Goff, H.D. and Hartel, R.W. (Eds.) (2013). Ice cream structure. In Ice Cream. $7^{\text {th }}$ ed, p. 325-333. New York: Springer. https://doi.org/10.1007/978-1-46146096-1_11

Hartel, R.W. (1996). Ice crystallization during the manufacture of ice cream. Trends Food Science and Technology, 7(10), 315-321. https:// doi.org/10.1016/0924-2244(96)10033-9

Kilcast, D. and Clegg, S. (2002). Sensory perception of creaminess and its relationship with food structure. Food Quality and Preference, 13(7-8), 609-623. https://doi.org/10.1016/S0950-3293(02)00074-5

Marshall, R.T., Goff, H.D. and Hartel, R.W. (2003). In Hartel, R.W. (Ed.). Ice cream. $3^{\text {rd }}$ ed., p. 203-349. New York: Aspen Publishers. https:// doi.org/10.1007/978-1-4615-0163-3

Moeenfard, M. and Tehrani, M.M. (2008). Effect of some stabilizers on the physicochemical and sensory properties of ice cream type frozen yogurt. American -Eurasian Journal of Agriculture and Environmental Science, 4(5), 584-589.

Muse, M.R. and Hartel, R.W. (2004). Ice cream structural elements that affect melting rate and hardness. Journal of Dairy Sciences, 87(1), 1-10. https://doi.org/10.3168/jds.S0022-0302(04)73135-5

Parid, D.M., Rahman, N.A.A., Baharuddin, A.S., Mohammed, M.A.P., Johari, A.M. and Razak, S.Z.A. (2018). Synthesis and characterization of carboxymethyl cellulose from oil palm empty fruit bunch stalk fibres. BioResources, 13(1), 535-554. https://doi.org/10.15376/biores.13.1.535-554

Rahman, N.A.A., Fowler, A. and Martin, P.J. (2013). Wall slip and viscous dissipation in ice cream pipe rheometry. Journal of Food Engineering, 119(4), 731-737.

https://doi.org/10.1016/ j.jfoodeng.2013.06.048

Rosalina, P.S. and Richard, W.H. (2004). Effects of overrun on structural and physical characteristics of ice cream. International Dairy Journal, 14, 255-262. https://doi.org/10.1016/j.idairyj.2003.08.005 
Sakurai, K., Kokubo, S., Hakamata, K., Tomita, M. and Yoshida, S. (1996). Effect of production conditions on ice cream melting resistance and hardness. Milchwissenschaft, 51(8), 451.

Taylor, A.J. and Linforth, R.S.T. (1996). Flavour release in the mouth. Trends in Food Science and Technology, 7(12), 342-346. https://doi.org/10.1016/ S0924-2244(96)10046-7 